\title{
Human Breast Milk Bacteriome in Health and Disease
}

\author{
Anna Ojo-Okunola ${ }^{1, *(\mathbb{D}}$, Mark Nicol ${ }^{1,2}$ and Elloise du Toit ${ }^{1}$ \\ 1 Division of Medical Microbiology, Department of Pathology, University of Cape Town, Observatory, \\ Cape Town 7925, South Africa; mark.nicol@uct.ac.za (M.N.); elloisedutoit@gmail.com (E.d.T.) \\ 2 Division of Medical Microbiology, National Health Laboratory Service, Observatory, \\ Cape Town 7925, South Africa \\ * Correspondence: annas2343@gmail.com; Tel.: +27-83-492-5284
}

Received: 28 September 2018; Accepted: 16 October 2018; Published: 3 November 2018

check for updates

\begin{abstract}
It is well-known that, beyond nutritional components, human breast milk (HBM) contains a wide variety of non-nutritive bio-factors perfectly suited for the growing infant. In the pre-2000 era, HBM was considered sterile and devoid of micro-organisms. Though HBM was not included as part of the human microbiome project launched in 2007, great strides have been made in studying the bacterial diversity of HBM in both a healthy state and diseased state, and in understanding their role in infant health. HBM provides a vast array of beneficial micro-organisms that play a key role in colonizing the infant's mucosal system, including that of the gut. They also have a role in priming the infant's immune system and supporting its maturation. In this review, we provide an in-depth and updated insight into the immunomodulatory, metabolic, and anti-infective role of HBM bacteriome (bacterial community) and its effect on infant health. We also provide key information from the literature by exploring the possible origin of microbial communities in HBM, the bacterial diversity in this niche and the determinants influencing the HBM bacteriome. Lastly, we investigate the role of the HBM bacteriome in maternal infectious disease (human immunodeficiency virus (HIV) and mastitis)), and cancer. Key gaps in HBM bacterial research are also identified.
\end{abstract}

Keywords: bacteriome; human breast milk; bacterial community; mastitis; human immunodeficiency virus (HIV); cancer

\section{Introduction}

Human breast milk (HBM) is a complex, specific, physiological fluid universally known as the optimal post-natal source of nutrition for infants [1-3]. It consists not only of essential nutrients (vitamins, minerals, protein), cells, hormones, immunological and immunomodulatory factors (cytokines, immunoglobulin A, microRNAs), but also of non-nutritive bio-molecules (glyco-conjugates, oligosaccharides) [4] and a vast array of microbes (the bacteria, archaea, viruses, protozoa and anaerobic fungi) known as the human milk microbiota [5-7].

\section{Human Breast Milk Bacteriome}

The presence of bacteria in HBM as both an evolutionary strategy subsequent to the divergence of mammals millions of years ago and an effect of natural selection has made it uniquely suited to nourish infants [8]. For example, an infant consuming an average of $800 \mathrm{~mL} \mathrm{HBM}$ per day has been reported to ingest $10^{4}-10^{6}$ commensal bacteria [9]. These bacteria are not merely present or transient but are rather transcriptionally active and functioning participants in the infant's gut community [10]. These bacteria serve as a physiological and continuous source of commensal and potential probiotic bacteria to the infant's gut $[2,11,12]$. In addition to the role of HBM bacteria in infants, these bacteria also help in maintaining the mother's health, i.e., aiding in the prevention of mastitis [13]. 


\section{Bacterial Diversity in Human Breast Milk}

In the pre-2000 era, HBM was considered sterile and devoid of micro-organisms [2]. However, in 2003, Martin et al. described the presence of commensal and probiotic bacteria in HBM. The study used culture-dependent techniques and found, in all samples, a predominance of the lactic acid bacteria Lactobacillus gasseri and Lactobacillus fermentum [14]. Lactic acid bacteria, including species of genera Lactobacillus and Bifidobacterium, are of interest in matters of human health. They are known to limit the growth of potential pathogenic organisms in the gastrointestinal tract due to their ability to produce acetate and lactate from the metabolism of ingested sugars. Bifidobacterium was not initially regarded as a typical lactic acid bacteria due to their unrelated genetic structure, however, their habitat overlaps with that of lactic acid bacteria and they produce lactic acid as an end-product of fermentation [15]. According to $\mathrm{FAO} / \mathrm{WHO}$, select lactic acid bacteria strains with proven probiotic properties are thereby referred to as probiotics [16].

These early descriptions of bacterial diversity in HBM came from utilizing culture-dependent techniques which allowed for the detection of facultative anaerobic bacteria, their close-relatives Gram-positive bacteria and lactic acid bacteria in aseptically collected HBM [9,14]. The more fastidious organisms, such as strict anaerobes which require a more exacting culture media and stricter growth requirements, were not detected [11]. More recently, and only using culture-independent DNA-based techniques including denaturing gradient gel electrophoresis (DGGE), temperature gradient gel electrophoresis (TGGE) and next generation sequencing (NGS), additional bacterial genera have been detected. These include the obligate anaerobes, particularly Bifidobacterium spp., Bacteroides spp., and members of the Clostridia class [5,17].

In the first NGS study of HBM samples, the diversity of bacterial communities, or bacteriomes, was characterized using 454 pyrosequencing to target the 16S rRNA gene. The most abundant genera were found to be Streptococcus, Staphylococcus, Serratia and Corynebacterium [5]. In another study by Jost et al. (2013), NGS revealed gut anaerobes including Clostridia whose members produce the metabolite butyrate which helps maintain colon health [11]. The bacterial diversity of HBM over the course of lactation (colostrum, transitional and mature milk) was also characterized using same technique [18]. Several micro-organisms including Streptococcus spp., Staphylococcus spp. and lactic acid bacteria (Weisella spp. and Leuconostoc spp.) were found throughout; mature milk samples, however, possessed additional bacterial genera that typically dwell in the oral cavity [18]. Similar bacterial diversity patterns were seen using NGS with Illumina MiSeq [19], as well as in two studies using metagenomic approaches [6,13]. While $16 \mathrm{~S}$ amplicon approaches target bacteria, metagenomic studies allow for the detection of other microorganisms such as fungi, protozoa, archaea and viruses. Another advantage of metagenomic methods is that they allow for taxonomic identification at the species level, whereas $16 \mathrm{~S}$ can only confidently identify organisms until the genus level. Firmicutes and Proteobacteria were the dominant phyla observed in both the metagenomic studies and the $16 S$ sequencing studies. At the genus level, however, the relative abundance of Streptococcus and Staphylococcus was relatively low [6,13]. A systematic review of the HBM bacteriome using culture-independent techniques has revealed that these two genera (Staphylococcus and Streptococcus) may be universally predominant regardless of differences in geographical area or methodological approach [20].

\subsection{The Core Milk Bacteriome?}

Hunt and co-workers (2011) suggested that there is a "core" HBM bacteriome of nine bacterial genera including Staphylococcus, Streptococcus, Serratia, Pseudomonas, Corynebacterium, Ralstonia, Propionibacterium, Sphingomonas, and Bradyrhizobium. The operational taxonomic units (OTU) were found to represent about half of the observed microbial community, though their relative abundances varied quite significantly among women [5]. Since then, various studies have confirmed the hypothesis of a core bacteriome $[13,19,21]$. This "core" was not observed across colostrum samples, suggesting that the acquisition of a stable microbial profile is gradual [22]. 
The core bacteriome may consist of species needed for maintaining efficient ecosystem homeostasis whose loss (or gain) may negatively impact the structure and function of other members in the ecosystem [23]. Interestingly, however, it is assumed that the core bacteria are less affected by the environmental factors (diet, obesity, stress) which are known to alter the composition of the other bacteriome [24].

Differences in this "core" bacteriome have been reported across various studies [5,19,21]. These differences could be a result of the following factors: sample collection methods (electric pump vs. manual expression, skin cleaning vs. decontamination), use of different DNA extraction kits, storage conditions and freeze/thaw cycles of samples, sequencing platforms, possible biases introduced by the use of primers with the amplification of different 16S rRNA gene hypervariable regions and use of different pipelines in analyzing sequence reads [6,21]. Despite these factors, the identified core bacteria genera commonly included Staphylococcus, Streptococcus, Lactobacillus and Propionibacterium (see Figure 1). Formal meta-analysis of studies characterizing the core HBM bacteriome in different geographical locations, however, is required.

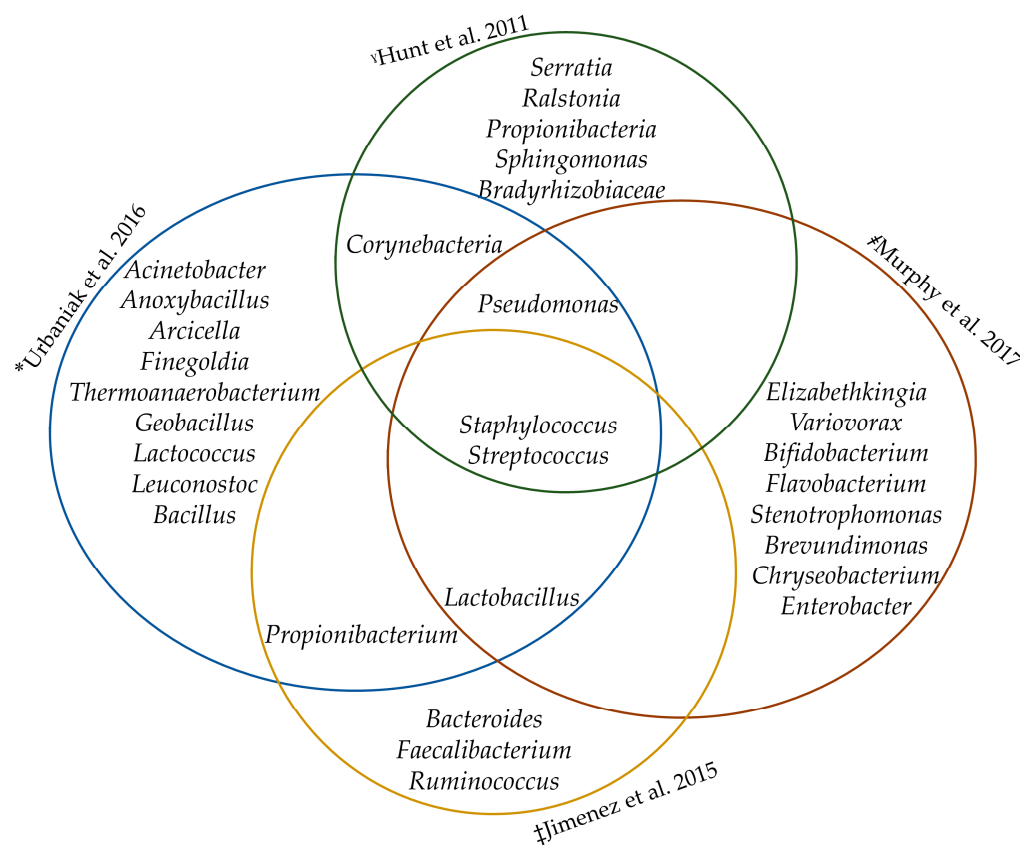

Figure 1. The core human breast milk bacteriome. *QIAamp ${ }^{\circledR}$ DNA Stool Kit (Qiagen), V6 region of bacterial 16S rRNA gene, Ion Torrent platform. 'QIAmp DNA Stool Mini Kit (Qiagen), V3-V4 region of bacterial 16S rRNA gene, Illumina MiSeq platform. ‡QIAamp DNA Mini Kit (Qiagen) with previous mechanical and enzymatic lysis, V1-V2 region, Pyrosequencing.

\subsection{Origin of The Human Breast Milk Bacteriome}

There have been several debates about the origin of bacterial communities in HBM. In 2003, Martin et al. used randomly amplified polymorphic DNA (RAPD) polymerase chain reaction (PCR) to analyze lactic acid bacteria from HBM, breast skin and areola. It was observed that the lactic acid bacteria isolated from HBM had DNA profiles that were different from those isolated from either the breast skin or the mammary areola [14]. Obligate anaerobes (Bacteroides spp. and/or Bifidobacterium spp.) which are unlikely to survive the aerobic conditions of the breast skin have also been isolated from HBM [12,21].

In addition, an experiment conducted by Hunt et al. (2011) showed that although the bacteriome in the sebaceous skin and HBM share many of the same phylotypes, differences were found. Streptococcus, one of the most abundant genera in HBM samples globally, was only a minor component of the sebaceous skin bacteriome. Propionibacterium, on the other hand, reported as one of the most abundant 
in sebaceous skin genera, was not among the most abundant genera found in HBM samples [5]. Bacteriome found in HBM using Illumina MiSeq were distinct from the areolar skin in both composition and diversity [25].

\subsubsection{Retrograde Flow}

It is possible that some bacteria found in HBM come from the transfer of oral and skin bacteria which enter the mammary ducts during suckling in a process called retrograde flow [26]. This hypothesis was investigated by Ramsay and colleagues who used ultrasound imaging to demonstrate that there is a high degree of retrograde flow of milk from the infants' mouth back into the mammary ducts during breastfeeding, providing an ideal route for the exchange of bacteria back into the mammary ducts [26]. Streptococcus, one of the most abundant bacterial genera in the HBM bacteriome, also dominates the salivary bacteriome $[5,27]$ lending support to the retrograde flow mechanism, however, investigation into whether both bacterial communities share identical species and strains of Streptococcus spp. is warranted.

\subsubsection{Gut-Mammary-Axis}

Another more recent hypothesis on the origin of the HBM bacteriome is the entero-mammary pathway where non-pathogenic, intestinally derived bacteria may be transported to other locations such as mucosal surfaces of the lactating mammary gland through the endogenous cellular pathway known as the mononuclear cells $[2,3,28]$.

The translocation of the gut bacteria to the mammary glands is aided by the physiological and hormonal changes during late pregnancy and the increased permeability of the intestinal epithelial lining [27]. In support of this hypothesis, animal studies have shown increased bacterial translocation of both aerobic and anaerobic organisms from the gut to the mesenteric lymph nodes and mammary glands in pregnant and lactating mice [28].

In addition, Zhou et al. have found similar bacterial signatures in the dendritic cells (DC), breast milk (BM), intestines and lymph nodes of lactating mice [29] suggesting translocation of bacteria from the intestines by the DC, into the lymphatic system and carried through to the mammary gland environment.

\subsubsection{Mammary Gland Bacteriome}

The human breast tissue bacteriome has recently been determined [30,31] from breast tissue biopsies collected from different sites within the breast. The viability of the bacteria was confirmed by culture. As in HBM bacteriome, the principal phylum, Proteobacteria, was the major phylum detected in human breast tissue bacteriome. Moreover, the two microbial communities share several bacteria genera [6,21].

The breast ductal bacteriome has recently been described by analyzing nipple aspirate fluid (NAF) [32]. NAF is regularly secreted by the epithelial cells lining the breast ducts that can be collected non-invasively from the duct in most women by applying negative pressure with a syringe attached to a suction cup [33]. The duct is in constant communication with the external environment through the areola. There is likely to be interaction of microbes between these various compartments in the mammary environment.

Together, we may view the ecological niches in the human bacteriome, not as isolated environments, but as a network of inter-related communities experiencing constant exchange [5]. It seems likely that the HBM bacteriome may be constantly influenced by exposure to other microbial populations associated with mother and child.

\section{Factors Which May Affect the Human Breast Milk Bacteriome}

Many factors have been identified to contribute to the variability of the HBM bacterial community between different women and within the same woman while she is experiencing different physiological, 
hormonal and pathological conditions. Both maternal and infant factors have been shown to contribute to this variation. While factors such as infant gender have been shown to have no influence [19], studies have shown that maternal health and geographical location play a major role (see Table 1).

1. Mode of delivery: An estimate by qPCR [34,35] claims that women who delivered via caesarean section (CS) have been shown to have a lower abundance of Lactobacillus spp. (L. fermentum and L. salivarius), Bifidobacterium spp. when compared with the higher bacterial counts of women who delivered vaginally. The HBM of mothers who had elective CS also showed decreased members of the family Leuconostocaceae and increased Carnobacteriaceae, when compared with women who delivered vaginally [18]. However, in a study by Urbaniak and colleagues which utilized a more robust statistical analysis [19], no difference in bacterial profiles was observed between women who delivered vaginally and those who delivered via emergency CS. It was suggested that this could be due to the initiation of the labor process, including physiological stress and hormonal signals which may influence increased permeability of intestinal epithelial lining for translocation [18,19].

2. Maternal weight: Higher levels of Staphylococcus spp. and lower levels of Bifidobacterium spp. were observed in HBM from overweight mothers as compared with normal-weight mothers [36]; and a less diverse bacterial community has also been observed in obese mothers [18]. This may be due to the metabolic capacity of the bacteriome of obese individuals which has an increased capacity to harvest energy from diet [37].

3. Antibiotics and Chemotherapy: A lower abundance of lactobacilli and bifidobacteria was detected in HBM of mothers who were exposed to antibiotics during the perinatal stage [35]. Exposure to anti-cancer chemotherapy also resulted in a reduction of the genera Bifidobacterium, Eubacterium, Staphylococcus and Cloacibacterium [38].

4. Maternal health: Gronlund et al. (2007) described that the bacteriome is influenced by maternal health. In his study using direct PCR analysis, allergic women exhibited a significantly lower Bifidobacterium spp. in their BM, with their infants also having lower fecal bifidobacteria counts [39]. African women with HIV-RNA in their HBM had an increased bacterial diversity and higher abundance of Lactobacillus spp. compared to controls [40]. Lower abundance of Bifidobacterium spp. and Bacteroides fragilis group have been detected in HBM of women with celiac disease [41].

5. Lactation stage: A higher bacterial diversity but lower total bacterial count and less bifidobacteria species were detected in colostrum when compared with mature HBM [18]. Bifidobacterium spp. and Enterococcus spp. counts, along with total bacteria increased as the lactation stage progressed [34]. In a similar study, however, transition milk samples were observed to possess higher diversity than colostrum and mature milk [34,42].

6. Geographical location: The bacterial genera found in HBM of Spanish mothers were different to those of Americans [5,42], or Finnish women [18] using sequencing techniques with a similarly high throughput. In a study by Kumar et al., Chinese women had high levels of Actinobacteria in comparison to the similarly high levels of Bacteroidetes detected in Spanish women [43].

7. Gestational age: Bifidobacterium spp. were observed to be higher in HBM of women with term babies than in preterm gestation. 
Table 1. Factors influencing human breast milk bacteriome.

\begin{tabular}{|c|c|c|}
\hline $\begin{array}{l}\text { Factors Influencing Human } \\
\text { Breast Milk Bacteriome }\end{array}$ & Bacteriome & References \\
\hline \multicolumn{3}{|l|}{ Mode of delivery } \\
\hline Caesarean section & $\begin{array}{l}\downarrow \text { Bifidobacterium spp., } \uparrow \text { Proteobacteria, } \downarrow \\
\text { Lactobacillus spp. (L. fermentum and L. salivarius), } \\
\downarrow \text { Leuconostocaceae, } \uparrow \text { Carnobacteriaceae }\end{array}$ & {$[18,34,35]$} \\
\hline Vaginal delivery & $\uparrow$ Bifidobacterium spp., $\uparrow$ Lactobacillus spp. & {$[34,35]$} \\
\hline \multicolumn{3}{|l|}{ Maternal weight } \\
\hline Overweight mothers & $\uparrow$ Staphylococcus, $\downarrow$ Bifidobacterium & [36] \\
\hline Obese mothers & Less diverse bacterial community & [18] \\
\hline \multicolumn{3}{|l|}{ Antibiotic and Chemotherapy } \\
\hline Perinatal antibiotics usage & $\downarrow$ Lactobacillus/Bifidobacterium & [35] \\
\hline Chemotherapy & $\begin{array}{c}\downarrow \text { Bifidobacterium, } \downarrow \text { Eubacterium, } \downarrow \text { Staphylococcus } \\
\text { and } \downarrow \text { Cloacibacterium }\end{array}$ & [38] \\
\hline \multicolumn{3}{|l|}{ Maternal health } \\
\hline Allergy & $\downarrow$ Bifidobacterium & [39] \\
\hline Celiac disease & $\downarrow$ Bifidobacterium spp., $\downarrow$ Bacteroides fragilis group & [41] \\
\hline HIV & $\uparrow$ Bacterial diversity, $\uparrow$ Lactobacillus spp. & [40] \\
\hline \multicolumn{3}{|l|}{ Geographical location } \\
\hline Spanish women & $\uparrow$ Bacteroidetes & [43] \\
\hline Chinese women & $\uparrow$ Actinobacteria & [43] \\
\hline \multicolumn{3}{|l|}{ Lactation stage } \\
\hline Colostrum & $\begin{array}{c}\uparrow \text { Bacterial diversity, } \downarrow \text { Bifidobacterium spp., } \downarrow \\
\text { Total bacterial count }\end{array}$ & [18] \\
\hline Transition milk & $\begin{array}{c}\uparrow \text { Bifidobacterium, } \uparrow \text { Enterococcus spp. counts, } \uparrow \\
\text { Total bacteria count }\end{array}$ & {$[34,42]$} \\
\hline
\end{tabular}

HIV: human immunodeficiency virus.

\section{Plausible Functions of Human Breast Milk Bacteria}

The HBM bacterial communities play a role in reduction of the incidence and severity of infections in the breastfed infant via mechanisms such as competitive exclusion and production of antimicrobial compounds. HBM bacteriome also improve the intestinal barrier function by increasing mucin production and reducing intestinal permeability [2,3].

\subsection{Vertical Transmission and Seeding of Infant Gut by HBM Bacteria}

Evidence for vertical transmission of maternal bacteria, via milk, to the infant's gut has been shown in humans [12,14]. Lactobacillus spp. sequences isolated from infant feces showed identical patterns to those found in their respective maternal HBM but differed from the profiles found in the maternal vagina [14]. Identical bacterial strains of bifidobacterium (Bifidobacterium breve and Bifidobacterium longum subsp. longum), and Lactobacillus plantarum have been confirmed in HBM and infant feces of mother-infant pairs, suggesting vertical transfer from the mother's milk to the infant $[21,44,45]$.

Recently, additional supporting evidence for vertical transmission of maternal microbes has been published. Shotgun metagenomics was used to demonstrate the transfer of specific strains of Bifidobacterium spp., Ruminococcus bromii, and Coprococcus comes within different mother-infant pairs [10]. Another study compared the fecal bacteriome of breastfed infants, whose gut is dominated by Bifidobacterium spp. and Lactobacillus spp. transmitted from HBM, to that of formula-fed infants, whose gut is predominantly colonized by enterococci, enterobacteria and Clostridium difficile-a pathogen associated with enteric and atopic diseases [46,47]. 


\subsection{Anti-Infective Activities of HBM Bacteria}

In vitro studies show that Lactobacillus rhamnosus and Lactobacillus crispatus, isolated from HBM have anti-infective properties against Staphylococcus aureus (S. aureus). S. aureus has been implicated in mastitis [9], antibiotic-resistant nosocomial infections, and neonatal infections. HBM-derived lactobacilli strains, particularly Lactobacillus salivarius (L. salivarius) CECT5713, produce not only in vitro antibacterial activity, but also a protective effect against Salmonella enterica serovar Cholerasuis (S. enterica) CECT4155 in animal models. This is mediated through inhibiting the adhesion of S. enterica to mucins and increasing the likelihood of survival of infected mice [48].

Additionally, HBM lactic acid bacteria protect the physiological environment of the gut through mechanisms such as the production of organic acids and the lowering of $\mathrm{pH}$ to inhibit the growth of various facultative and anaerobic bacteria $[48,49]$.

\subsection{Immuno-Modulatory Activities of HBM Bacteria}

HBM bacteria provide a source of bifidobacteria to the infants' gut. Bifidobacteria in turn activate T-regulatory cells which can result in improved resistance to pathogenic microorganisms [2,46]. In addition, the human milk metagenome has been shown to contain immunomodulatory DNA motifs which may help decrease exaggerated inflammatory responses to colonizing bacteria [6]. HBM derived probiotic strains, Lactobacillus fermentum CECT5716 and Lactobacillus salivarius CECT5713, have demonstrated in vitro immunomodulatory activity by modulating the activation of peripheral blood mononuclear cell (PBMC) subsets, CD8+ natural killer cells, Treg cells, and several cytokines and chemokines. This effect was not seen with probiotic bacteria of non-milk origin [50].

\subsection{Anti-Allergic Properties of HBM Bacteria}

A beneficial association has been proposed between HBM lactic acid bacteria and allergies. For example, animal studies have shown that probiotic lactobacilli (of HBM origin), Lactobacillus gasseri together with Lactobacillus coryniformis, decrease the occurrence and severity of allergic responses to cow milk protein [51]. Although a randomized, controlled trial showed that probiotic supplementation in the first six months of life did not reduce the risk of atopic eczema [52], other studies found that supplementation with specific Lactobacillus spp. and/or Bifidobacterium spp. in mothers led to a reduced infant eczema at one year and two years of age [53,54]. The Hygiene Hypothesis suggests that the anti-allergy properties of probiotics are due to the down-regulation in the production of Th2 cytokines by inducing a Th1 response [51]. Disturbance in the regulation of the immune system is considered an underlying cause of allergies [55].

It is also interesting to note that the presence of viridans streptococci, one of the dominant bacterial groups in HBM, seems to be a feature of a healthy infant gut in contrast to that of atopic infants whose gut is dominated by Klebsiella spp. [56]. Animal studies have shown that defective maturation of the immune system in animals that lack appropriate host-microbe interactions during early life makes them prone to allergic immune responses. This defective immune maturation occurs with the introduction of even a single strain of bacteria such as Bifidobacterium spp. during the neonatal phase [57].

\subsection{Metabolic Activities of HBM Bacteria}

HBM bacteria are essential for the digestion of oligosaccharides (the fourth main component of HBM). Infants lack the necessary enzymes to digest these and, instead, the HBM microbes ingested during feedings break them down into short chain fatty acids (SCFA); this end-product also serves as one of the main energy sources for colonocytes [58]. This is helpful for increased nutrient absorption as the gut of an infant is much shorter than in adults leading to quick transit of food [42]. 


\subsection{Anti-Tumor Properties of HBM Bacteria}

HBM bacteriome may have an anti-tumor role. In vitro studies have demonstrated that the heat-killed cells and cytoplasmic fractions of Enterococcus faecalis and Staphylococcus hominis isolated from HBM possess anti-tumor activity against a breast cancer cell line [59]. Another in vitro study has demonstrated the therapeutic, anti-cancer activity of lactic acid bacteria, Lactococccus lactis subsp. lactis, against colon cancer [60], This is relevant to both mother and infant health.

\section{Implications of the Human Breast Milk Bacteriome in Disease}

\subsection{Mastitis}

Lactational mastitis is an inflammatory condition of the mammary gland that occurs in about $30 \%$ of breastfeeding women [61,62]. It is characterized by local symptoms (localized warmness and soreness on the affected breast, pain, redness, swelling of the breast), in addition to systemic symptoms (fever). It is also a major reason breastfeeding (BF) is discontinued [63,64].

Mastitis is a dysbiosis of the HBM bacteriome characterized by rapid growth of opportunistic pathogenic bacteria including members of Staphylococcus and/or Streptococcus, Corynebacterium and depletion of commensal bacteria (Lactococcus and Lactobacillus) $[61,65,66]$. In acute mastitis, the bacteria count of Staphylococcus aureus (S. aureus) is said to increase greatly to about $4.0 \log 10 \mathrm{cfu} / \mathrm{mL}$ from 1.5-3.0 $\log 10 \mathrm{cfu} / \mathrm{mL}$ in healthy subjects. Another species, Staphylococcus epidermidis (S. epidermidis), normally appearing on skin and mucosa, is an under-recognized causative agent of lactational mastitis. This lack of recognition may occur if the clinician believes its presence stems from contamination of HBM samples with skin flora [61], however, recent studies have shown it plays an increasing role [13].

Coagulase-negative staphylococci (CNS) and S. epidermidis have been isolated in HBM of women with chronic mastitis. The chronic nature is because S. epidermidis forms biofilms and is resistant to many antibiotics [64]. Recent studies also show that the HBM metagenome in women with mastitis is different based on the stage/type of infection. While S. aureus was the most common etiological agent of acute mastitis, S. epidermidis was found to be the most common bacteria in subacute mastitis [13].

A reduced bacterial diversity and species richness has been observed in HBM of women with mastitis $[13,66]$. Phage related sequences were also observed in HBM of women with acute mastitis. This is because the virulence factors of $S$. aureus are encoded inside phages, making it easier for the bacteria to evade the host's immune system [13].

Patel et al. (2017) observed members of the genus Staphylococcus to be differentially abundant in sub-acute mastitis. Genes related to bacterial chemotaxis and invasion of epithelial cells, bacterial motility proteins and secretion system were enriched in women having sub-acute and acute mastitis [66].

A randomized clinical trial has shown that HBM derived probiotics, Lactobacillus salivarius CECT5713 and Lactobacillus gasseri CECT5714, when compared with antibiotics [65], are a complementary and effective substitute for the treatment and control of mastitis.

\subsection{Human Immunodeficiency Virus (HIV)}

HBM of women infected with HIV has been shown to have a different bacterial composition compared with non-infected women. An increase in both bacterial diversity and Lactobacillus spp. frequency has been observed. In contrast, Staphylococcus hominis (S. hominis) and S. aureus were significantly reduced [40] in HIV-infected women. The reduction of these two Staphylococcus species may be due to the inhibitory features of lactic acid bacteria against $S$. aureus [40]. In addition, a pathological or disturbed HIV-positive immune system could be a reason for the observed results. In a similar study, however, there was no difference either in bacterial diversity or in the bacterial profiles between HIV-positive and HIV-negative women [67]. The discrepancies in these results are unknown but could, however, be due to a difference in geological location, methodological differences or the small sample sizes used in the later study. 


\subsection{Cancer}

Although there has been no direct study on breast milk bacteriome and (breast) cancer, as women with cancer seldom breastfeed, the microbial ecology of other compartments within the mammary environment such as the breast tissue bacteriome and breast ductal bacteriome (using nipple aspirate fluid) have been linked to cancer [32,68].

Microbial dysbiosis was implicated in breast cancer in a study by Urbaniak and colleagues. There was a depletion of the lactic acid bacteria, Lactococcus spp. and Streptococcus spp., and an increased abundance of Bacillus spp., Staphylococcus spp. and the family Comamonadaceae and Enterobacteria. Escherichia coli isolated from breast cancer patients in the same study induced DNA double-stranded breaks [68].

Bacteria may have a systemic influence in the host, promoting, regulating and training the immune system [69]. Bacteria maintain the health of breast tissue by stimulating resident immune cells. In dysbiosis, a condition characterized by the reduction of specific bacterial taxa, there may be lower immune cell stimulation by such bacteria. This in turn creates an environment which may be conducive for breast tumor formation. Xuan et al. found that compared with the adjacent normal tissue, there was a significant reduction of Sphingomonas yanoikuyae in breast cancer patients [70]. In a similar study, a member of the Sphingomonadaceae family was enriched in nipple aspirate fluid from healthy controls while Alistipes was enriched in breast cancer patients [32].

The mechanisms, e.g., inflammation and DNA damage, through which bacteria play a role in cancer should be studied further, using animal models, as it's unsure whether the association of specific bacteria with tumors could be due to their ability to thrive well in particular milieus or because they cause cancer [71].

\section{Conclusions}

In conclusion, the HBM bacteriome has been shown to play a role in anti-infection, immunomodulation and metabolic activity and is known to be influenced by maternal and socio-economic factors. A better understanding of the factors influencing HBM bacteriome may make it possible to manipulate bacterial communities to improve the health and development outcomes of infants. Lastly, the HBM bacteriome may be associated with, or cause, specific disease conditions.

\section{Gaps Identified}

1. There are very limited animal studies demonstrating the specific role of breast milk bacteria in disease conditions.

2. There are few integrative studies exploring the interplay between HBM bacteriome and its metabolites, and their collective role in diseased condition.

3. There is insufficient data on some of the identified HBM bacterial groups. It isn't enough to simply characterize the bacterial diversity of HBM; rather, the role that each of the bacterium play in maintaining the microbial ecology of the HBM bacteriome and their role in infant and maternal health must be understood.

4. There are few studies on HBM bacteriome and the factors influencing low socio-economic regions, such as many African settings. These regions also boast less research of infant nutrition and this research is necessary to know if there are any underlying genetic mechanisms involved.

Author Contributions: A.O.-O. wrote all versions of the manuscript; E.d.T. and M.N. supervised the project and reviewed all versions of the manuscript. All authors reviewed and approved the final manuscript.

Funding: Research reported in this publication was supported by the NIH Common Fund, through the Office of Strategic Coordination/Office of the NIH Director, National Institute of Environmental Health Sciences and National Human Genome Institute of Health of the National Institutes of Health under Award Number U54HG009824. The content is the sole responsibility of the authors and does not necessarily represent the official views of the National Institutes of Health. This research was also funded by the Bill and Melinda Gates Foundation 
Global Health Grant, grant number (opp1017641; opp1017579) and h3africa u01 award from the National Institutes of Health of the USA, grant number 1U01AI110466-01A1.

Acknowledgments: We want to thank Mamadou Kaba and Maria C. Collado for reviewing a previous edition of this manuscript.

Conflicts of Interest: The authors declare no conflicts of interest.

\section{References}

1. Agostoni, C.; Braegger, C.; Decsi, T.; Kolacek, S.; Koletzko, B.; Michaelsen, K.F.; Mihatsch, W.; Moreno, L.A.; Puntis, J.; Shamir, R.; et al. Breast-feeding: A commentary by the espghan committee on nutrition. J. Pediatr. Gastroenterol. Nutr. 2009, 49, 112-125. [CrossRef] [PubMed]

2. Civardi, E.; Garofoli, F.; Tzialla, C.; Paolillo, P.; Bollani, L.; Stronati, M. Microorganisms in human milk: Lights and shadows. J. Matern. Fetal Neonatal Med. 2013, 26, 30-34. [CrossRef] [PubMed]

3. Fernandez, L.; Langa, S.; Martin, V.; Jimenez, E.; Martin, R.; Rodriguez, J.M. The microbiota of human milk in healthy women. Cell Mol. Biol. 2013, 59, 31-42. [PubMed]

4. Aakko, J.; Kumar, H.; Rautava, S.; Wise, A.; Autran, C.; Bode, L.; Isolauri, E.; Salminen, S. Human milk oligosaccharide categories define the microbiota composition in human colostrum. Benef. Microbes 2017, 8 , 563-567. [CrossRef] [PubMed]

5. Hunt, K.M.; Foster, J.A.; Forney, L.J.; Schutte, U.M.; Beck, D.L.; Abdo, Z.; Fox, L.K.; Williams, J.E.; McGuire, M.K.; McGuire, M.A. Characterization of the diversity and temporal stability of bacterial communities in human milk. PLoS ONE 2011, 6, e21313. [CrossRef] [PubMed]

6. Ward, T.L.; Hosid, S.; Ioshikhes, I.; Altosaar, I. Human milk metagenome: A functional capacity analysis. BMC Microbiol. 2013, 13, 116. [CrossRef] [PubMed]

7. Boix-Amorós, A.; Martinez-Costa, C.; Querol, A.; Collado, M.C.; Mira, A. Multiple approaches detect the presence of fungi in human breastmilk samples from healthy mothers. Sci. Rep. 2017, 7, 13016. [CrossRef] [PubMed]

8. Goldman, A.S. Evolution of immune functions of the mammary gland and protection of the infant. Breastfeed. Med. 2012, 7, 132-142. [CrossRef] [PubMed]

9. Heikkila, M.P.; Saris, P.E. Inhibition of staphylococcus aureus by the commensal bacteria of human milk. J. Appl. Microbiol. 2003, 95, 471-478. [CrossRef] [PubMed]

10. Asnicar, F.; Manara, S.; Zolfo, M.; Truong, D.T.; Scholz, M.; Armanini, F.; Ferretti, P.; Gorfer, V.; Pedrotti, A.; Tett, A.; et al. Studying vertical microbiome transmission from mothers to infants by strain-level metagenomic profiling. Am. Soc. Microbiol. 2017, 2. [CrossRef] [PubMed]

11. Jost, T.; Lacroix, C.; Braegger, C.; Chassard, C. Assessment of bacterial diversity in breast milk using culture-dependent and culture-independent approaches. Br. J. Nutr. 2013, 110, 1253-1262. [CrossRef] [PubMed]

12. Jost, T.; Lacroix, C.; Braegger, C.P.; Rochat, F.; Chassard, C. Vertical mother-neonate transfer of maternal gut bacteria via breastfeeding. Environ. Microbiol. 2014, 16, 2891-2904. [CrossRef] [PubMed]

13. Jimenez, E.; de Andres, J.; Manrique, M.; Pareja-Tobes, P.; Tobes, R.; Martinez-Blanch, J.F.; Codoner, F.M.; Ramon, D.; Fernandez, L.; Rodriguez, J.M. Metagenomic analysis of milk of healthy and mastitis-suffering women. J. Hum. Lact. 2015, 31, 406-415. [CrossRef] [PubMed]

14. Martin, R.; Langa, S.; Reviriego, C.; Jiminez, E.; Marin, M.L.; Xaus, J.; Fernandez, L.; Rodriguez, J.M. Human milk is a source of lactic acid bacteria for the infant gut. J. Pediatr. 2003, 143, 754-758. [CrossRef] [PubMed]

15. Kenneth, T. Important Groups of Procaryotes, Today's Online Textbook of Bacteriology. Available online: http:/ / textbookofbacteriology.net/ (accessed on 15 September 2018).

16. Mohania, D.; Nagpal, R.; Kumar, M.; Bhardwaj, A.; Yadav, M.; Jain, S.; Marotta, F.; Singh, V.; Parkash, O.; Yadav, H. Molecular approaches for identification and characterization of lactic acid bacteria. J. Dig. Dis. 2008, 9, 190-198. [CrossRef] [PubMed]

17. Fouhy, F.; Ross, R.P.; Fitzgerald, G.F.; Stanton, C.; Cotter, P.D. Composition of the early intestinal microbiota: Knowledge, knowledge gaps and the use of high-throughput sequencing to address these gaps. Gut Microbes 2012, 3, 203-220. [CrossRef] [PubMed] 
18. Cabrera-Rubio, R.; Collado, M.C.; Laitinen, K.; Salminen, S.; Isolauri, E.; Mira, A. The human milk microbiome changes over lactation and is shaped by maternal weight and mode of delivery. Am. J. Clin. Nutr. 2012, 96, 544-551. [CrossRef] [PubMed]

19. Urbaniak, C.; Angelini, M.; Gloor, G.B.; Reid, G. Human milk microbiota profiles in relation to birthing method, gestation and infant gender. Microbiome 2016, 4, 1. [CrossRef] [PubMed]

20. Fitzstevens, J.L.; Smith, K.C.; Hagadorn, J.I.; Caimano, M.J.; Matson, A.P.; Brownell, E.A. Systematic review of the human milk microbiota. Nutr. Clin. Pract. 2016. [CrossRef] [PubMed]

21. Murphy, K.; Curley, D.; O'Callaghan, T.F.; O'Shea, C.A.; Dempsey, E.M.; O’Toole, P.W.; Ross, R.P.; Ryan, C.A.; Stanton, C. The composition of human milk and infant faecal microbiota over the first three months of life: A pilot study. Sci. Rep. 2017, 7, 40597. [CrossRef] [PubMed]

22. Jimenez, E.; Delgado, S.; Fernandez, L.; Garcia, N.; Albujar, M.; Gomez, A.; Rodriguez, J.M. Assessment of the bacterial diversity of human colostrum and screening of staphylococcal and enterococcal populations for potential virulence factors. Res. Microbiol. 2008, 159, 595-601. [CrossRef] [PubMed]

23. Shetty, S.A.; Hugenholtz, F.; Lahti, L.; Smidt, H.; de Vos, W.M. Intestinal microbiome landscaping: Insight in community assemblage and implications for microbial modulation strategies. FEMS Microbiol. Rev. 2017, 41, 182-199. [CrossRef] [PubMed]

24. Salonen, A.; Salojarvi, J.; Lahti, L.; de Vos, W.M. The adult intestinal core microbiota is determined by analysis depth and health status. Clin. Microbiol. Infect. 2012, 18, 16-20. [CrossRef] [PubMed]

25. Pannaraj, P.S.; Li, F.; Cerini, C.; Bender, J.M.; Yang, S.; Rollie, A.; Adisetiyo, H.; Zabih, S.; Lincez, P.J.; Bittinger, K.; et al. Association between breast milk bacterial communities and establishment and development of the infant gut microbiome. JAMA Pediatr. 2017, 171, 647-654. [CrossRef] [PubMed]

26. Ramsay, D.T.; Kent, J.C.; Owens, R.A.; Hartmann, P.E. Ultrasound imaging of milk ejection in the breast of lactating women. Pediatrics 2004, 113, 361-367. [CrossRef] [PubMed]

27. Rodriguez, J.M. The origin of human milk bacteria: Is there a bacterial entero-mammary pathway during late pregnancy and lactation? Adv. Nutr. 2014, 5, 779-784. [CrossRef] [PubMed]

28. Perez, P.F.; Dore, J.; Leclerc, M.; Levenez, F.; Benyacoub, J.; Serrant, P.; Segura-Roggero, I.; Schiffrin, E.J.; Donnet-Hughes, A. Bacterial imprinting of the neonatal immune system: Lessons from maternal cells? Pediatrics 2007, 119, e724-e732. [CrossRef] [PubMed]

29. Zhou, X.; Voigt, A.; Paveglio, S.; Weinstock, G.; Matson, A.; Davidovics, Z. Similar bacterial signatures in intestinal tissues, milk, and dendritic cells of lactating mice suggest a possible entero-mammary pathway. Gastroenterology 2017, 152, S172. [CrossRef]

30. Urbaniak, C.; Cummins, J.; Brackstone, M.; Macklaim, J.M.; Gloor, G.B.; Baban, C.K.; Scott, L.; O'Hanlon, D.M.; Burton, J.P.; Francis, K.P.; et al. Microbiota of human breast tissue. Appl. Environ. Microbiol. 2014, 80, 3007-3014. [CrossRef] [PubMed]

31. Hieken, T.J.; Chen, J.; Hoskin, T.L.; Walther-Antonio, M.; Johnson, S.; Ramaker, S.; Xiao, J.; Radisky, D.C.; Knutson, K.L.; Kalari, K.R.; et al. The microbiome of aseptically collected human breast tissue in benign and malignant disease. Sci. Rep. 2016, 6, 30751. [CrossRef] [PubMed]

32. Chan, A.A.; Bashir, M.; Rivas, M.N.; Duvall, K.; Sieling, P.A.; Pieber, T.R.; Vaishampayan, P.A.; Love, S.M.; Lee, D.J. Characterization of the microbiome of nipple aspirate fluid of breast cancer survivors. Sci. Rep. 2016, 6, 28061. [CrossRef] [PubMed]

33. Petrakis, N.L. Nipple aspirate fluid in epidemiologic studies of breast disease. Epidemiol. Rev. 1993, 15, 188-195. [CrossRef] [PubMed]

34. Khodayar-Pardo, P.; Mira-Pascual, L.; Collado, M.C.; Martinez-Costa, C. Impact of lactation stage, gestational age and mode of delivery on breast milk microbiota. J. Perinatol. 2014, 34, 599-605. [CrossRef] [PubMed]

35. Soto, A.; Martin, V.; Jimenez, E.; Mader, I.; Rodriguez, J.M.; Fernandez, L. Lactobacilli and bifidobacteria in human breast milk: Influence of antibiotherapy and other host and clinical factors. J. Pediatr. Gastroenterol. Nutr. 2014, 59, 78-88. [CrossRef] [PubMed]

36. Collado, M.C.; Laitinen, K.; Salminen, S.; Isolauri, E. Maternal weight and excessive weight gain during pregnancy modify the immunomodulatory potential of breast milk. Pediatr. Res. 2012, 72, 77-85. [CrossRef] [PubMed]

37. Turnbaugh, P.J.; Ley, R.E.; Mahowald, M.A.; Magrini, V.; Mardis, E.R.; Gordon, J.I. An obesity-associated gut microbiome with increased capacity for energy harvest. Nature 2006, 444, 1027-1131. [CrossRef] [PubMed] 
38. Urbaniak, C.; McMillan, A.; Angelini, M.; Gloor, G.B.; Sumarah, M.; Burton, J.P.; Reid, G. Effect of chemotherapy on the microbiota and metabolome of human milk, a case report. Microbiome 2014, 2, 24. [CrossRef] [PubMed]

39. Gronlund, M.M.; Gueimonde, M.; Laitinen, K.; Kociubinski, G.; Gronroos, T.; Salminen, S.; Isolauri, E. Maternal breast-milk and intestinal bifidobacteria guide the compositional development of the bifidobacterium microbiota in infants at risk of allergic disease. Clin. Exp. Allergy 2007, 37, 1764-1772. [CrossRef] [PubMed]

40. Gonzalez, R.; Maldonado, A.; Martin, V.; Mandomando, I.; Fumado, V.; Metzner, K.J.; Sacoor, C.; Fernandez, L.; Macete, E.; Alonso, P.L.; et al. Breast milk and gut microbiota in african mothers and infants from an area of high hiv prevalence. PLoS ONE 2013, 8, e80299. [CrossRef] [PubMed]

41. Olivares, M.; Albrecht, S.; De Palma, G.; Ferrer, M.D.; Castillejo, G.; Schols, H.A.; Sanz, Y. Human milk composition differs in healthy mothers and mothers with celiac disease. Eur. J. Nutr. 2015, 54, 119-128. [CrossRef] [PubMed]

42. Boix-Amoros, A.; Collado, M.C.; Mira, A. Relationship between milk microbiota, bacterial load, macronutrients, and human cells during lactation. Front. Microbiol. 2016, 7, 492. [CrossRef] [PubMed]

43. Kumar, H.; du Toit, E.; Kulkarni, A.; Aakko, J.; Linderborg, K.M.; Zhang, Y.; Nicol, M.P.; Isolauri, E.; Yang, B.; Collado, M.C.; et al. Distinct patterns in human milk microbiota and fatty acid profiles across specific geographic locations. Front. Microbiol. 2016, 7, 1619. [CrossRef] [PubMed]

44. Milani, C.; Mancabelli, L.; Lugli, G.A.; Duranti, S.; Turroni, F.; Ferrario, C.; Mangifesta, M.; Viappiani, A.; Ferretti, P.; Gorfer, V.; et al. Exploring vertical transmission of bifidobacteria from mother to child. Appl. Environ. Microbiol. 2015, 81, 7078-7087. [CrossRef] [PubMed]

45. Solís, G.; de los Reyes-Gavilan, C.G.; Fernández, N.; Margolles, A.; Gueimonde, M. Establishment and development of lactic acid bacteria and bifidobacteria microbiota in breast-milk and the infant gut. Anaerobe 2010, 16, 307-310. [CrossRef] [PubMed]

46. Walker, W.A.; Iyengar, R.S. Breast milk, microbiota, and intestinal immune homeostasis. Pediatr. Res. 2015, 77, 220-228. [CrossRef] [PubMed]

47. Azad, M.B.; Konya, T.; Maughan, H.; Guttman, D.S.; Field, C.J.; Chari, R.S.; Sears, M.R.; Becker, A.B.; Scott, J.A.; Kozyrskyj, A.L. Gut microbiota of healthy canadian infants: Profiles by mode of delivery and infant diet at 4 months. Can. Med. Assoc. J. 2013, 185, 385-394. [CrossRef] [PubMed]

48. Olivares, M.; Díaz-Ropero, M.P.; Martín, R.; Rodríguez, J.M.; Xaus, J. Antimicrobial potential of four lactobacillus strains isolated from breast milk. J. Appl. Microbiol. 2006, 101, 72-79. [CrossRef] [PubMed]

49. Fons, A.G.; Tuomo Karjalainen, M. Mechanisms of colonisation and colonisation resistance of the digestive tract part 2: Bacteria/bacteria interactions. Microb. Ecol. Health Dis. 2000, 12, 240-246.

50. Perez-Cano, F.J.; Dong, H.; Yaqoob, P. In vitro immunomodulatory activity of lactobacillus fermentum cect5716 and lactobacillus salivarius cect5713: Two probiotic strains isolated from human breast milk. Immunobiology 2010, 215, 996-1004. [CrossRef] [PubMed]

51. Lara-Villoslada, F.; Olivares, M.; Sierra, S.; Rodriguez, J.M.; Boza, J.; Xaus, J. Beneficial effects of probiotic bacteria isolated from breast milk. Br. J. Nutr. 2007, 98, S96-S100. [CrossRef] [PubMed]

52. Taylor, A.L.; Dunstan, J.A.; Prescott, S.L. Probiotic supplementation for the first 6 months of life fails to reduce the risk of atopic dermatitis and increases the risk of allergen sensitization in high-risk children: A randomized controlled trial. J. Allergy Clin. Immunol. 2007, 119, 184-191. [CrossRef] [PubMed]

53. Abrahamsson, T.R.; Jakobsson, T.; Böttcher, M.F.; Fredrikson, M.; Jenmalm, M.C.; Björkstén, B.; Oldaeus, G. Probiotics in prevention of ige-associated eczema: A double-blind, randomized, placebo-controlled trial. J. Allergy Clin. Immunol. 2007, 119, 1174-1180. [CrossRef] [PubMed]

54. Kim, J.Y.; Kwon, J.H.; Ahn, S.H.; Lee, S.I.; Han, Y.S.; Choi, Y.O.; Lee, S.Y.; Ahn, K.M.; Ji, G.E. Effect of probiotic mix (bifidobacterium bifidum, bifidobacterium lactis, lactobacillus acidophilus) in the primary prevention of eczema: A double-blind, randomized, placebo-controlled trial. Pediatr. Allergy Immunol. 2010, 21, e386-e393. [CrossRef] [PubMed]

55. Prokopakis, E.; Vardouniotis, A.; Kawauchi, H.; Scadding, G.; Georgalas, C.; Hellings, P.; Velegrakis, G.; Kalogjera, L. The pathophysiology of the hygiene hypothesis. Int. J. Pediatr. Otorhinolaryngol. 2013, 77, 1065-1071. [CrossRef] [PubMed] 
56. Kirjavainen, P.V.; Apostolou, E.; Arvola, T.; Salminen, S.J.; Gibson, G.R.; Isolauri, E. Characterizing the composition of intestinal microflora as a prospective treatment target in infant allergic disease. FEMS Immunol. Med. Microbiol. 2001, 32, 1-7. [CrossRef] [PubMed]

57. Rautava, S. Early microbial contact, the breast milk microbiome and child health. J. Dev. Orig. Health Dis. 2016, 7, 5-14. [CrossRef] [PubMed]

58. Maldonado, J.; Lara-Villoslada, F.; Sierra, S.; Sempere, L.; Gómez, M.; Rodriguez, J.M.; Boza, J.; Xaus, J.; Olivares, M. Safety and tolerance of the human milk probiotic strain lactobacillus salivarius cect5713 in 6-month-old children. Nutrition 2010, 26, 1082-1087. [CrossRef] [PubMed]

59. Hassan, Z.; Mustafa, S.; Rahim, R.A.; Isa, N.M. Anti-breast cancer effects of live, heat-killed and cytoplasmic fractions of enterococcus faecalis and staphylococcus hominis isolated from human breast milk. IN Vitro Cell. Dev. Biol. Anim. 2016, 52, 337-348. [CrossRef] [PubMed]

60. Kim, J.Y.; Woo, H.J.; Kim, Y.S.; Kim, K.H.; Lee, H.J. Cell cycle dysregulation induced by cytoplasm of lactococcus lactis ssp lactis in snuc2a, a colon cancer cell line. Nutr. Cancer 2003, 46, 197-201. [CrossRef] [PubMed]

61. Delgado, S.; Arroyo, R.; Martin, R.; Rodriguez, J.M. Pcr-dgge assessment of the bacterial diversity of breast milk in women with lactational infectious mastitis. BMC Infect. Dis. 2008, 8, 51. [CrossRef] [PubMed]

62. Foxman, B.; D'Arcy, H.; Gillespie, B.; Bobo, J.K.; Schwartz, K. Lactation mastitis: Occurrence and medical management among 946 breastfeeding women in the united states. Am. J. Epidemiol. 2002, 155, 103-114. [CrossRef] [PubMed]

63. Cullinane, M.; Amir, L.H. In response to "microbial diversity in milk of women with mastitis: Potential role of coagulase-negative staphylococci, viridans group streptococci, and corynebacteria". J. Hum. Lact. 2017, 33, 815-816. [CrossRef] [PubMed]

64. Delgado, S.; Arroyo, R.; Jimenez, E.; Marin, M.L.; del Campo, R.; Fernandez, L.; Rodriguez, J.M. Staphylococcus epidermidis strains isolated from breast milk of women suffering infectious mastitis: Potential virulence traits and resistance to antibiotics. BMC Microbiol. 2009, 9, 82. [CrossRef] [PubMed]

65. Arroyo, R.; Martín, V.; Maldonado, A.; Jiménez, E.; Fernández, L.; Rodríguez, J.M. Treatment of infectious mastitis during lactation: Antibiotics versus oral administration of lactobacilli isolated from breast milk. Clin. Infect. Dis. 2010, 50, 1551-1558. [CrossRef] [PubMed]

66. Patel, S.H.; Vaidya, Y.H.; Patel, R.J.; Pandit, R.J.; Joshi, C.G.; Kunjadiya, A.P. Culture independent assessment of human milk microbial community in lactational mastitis. Sci. Rep. 2017, 7, 7804. [CrossRef] [PubMed]

67. Bender, J.M.; Li, F.; Martelly, S.; Byrt, E.; Rouzier, V.; Leo, M.; Tobin, N.; Pannaraj, P.S.; Adisetiyo, H.; Rollie, A.; et al. Maternal hiv infection influences the microbiome of hiv uninfected infants. Sci. Transl. Med. 2016, 8, 100-349. [CrossRef] [PubMed]

68. Urbaniak, C.; Gloor, G.B.; Brackstone, M.; Scott, L.; Tangney, M.; Reid, G. The microbiota of breast tissue and its association with breast cancer. Appl. Environ. Microbiol. 2016, 82, 5039-5048. [CrossRef] [PubMed]

69. Belkaid, Y.; Hand, T. Role of the microbiota in immunity and inflammation. Cell 2014, 157, 121-141. [CrossRef] [PubMed]

70. Xuan, C.; Shamonki, J.M.; Chung, A.; DiNome, M.L.; Chung, M.; Sieling, P.A.; Lee, D.J. Microbial dysbiosis is associated with human breast cancer. PloS ONE 2014, 9, e83744. [CrossRef] [PubMed]

71. Sheikh, K. The breast has its own microbiome. Sci. Am. 2016, 20, 947-957. [CrossRef] [PubMed]

(C) 2018 by the authors. Licensee MDPI, Basel, Switzerland. This article is an open access article distributed under the terms and conditions of the Creative Commons Attribution (CC BY) license (http:// creativecommons.org/licenses/by/4.0/). 